\title{
Improving Peanut Growth and Yield Responses with Monoseeding and Paclobutrazol Applications in Southern China
}

Tingting Chen ${ }^{1 \#}$, Jialei Zhang ${ }^{2 \#}$, Xinyue Wang ${ }^{1}$, Ruier Zeng ${ }^{1}$, Lei Zhang ${ }^{1}$

10.18805/LRF-643

\begin{abstract}
Background: Peanut yields are affected by plant density and chemical controls.

Methods: A field experiment was conducted in Southern China to investigate the effects of population density and paclobutrazol applications on the growth and yield of peanuts with monoseeding and double seeding patterns.

Result: Paclobutrazol application could improve peanut yields. The highest peanut yields were observed with $250 \mathrm{mg} \mathrm{L}^{-1}$ paclobutrazol and a plant density of 235410 plants ha ${ }^{-1}$, with the monoseeding pattern. Our results suggest that monoseeding and paclobutrazol could be applied to enhance peanut yields in Southern China.
\end{abstract}

Key words: Arachis hypogaea L., Monoseeding, Paclobutrazol, Plant population, Yield.

\section{INTRODUCTION}

Peanut, Arachis hypogaea L., is a leguminous crop and an important source of oil and protein for humans that is cultivated in tropical and subtropical regions. In China, peanuts are grown on more than $5.0 \times 10^{6}$ ha, to ensure the supply of edible oils (Zhang et al. 2019). Traditional planting patterns mainly involve double- and multi-seed sowing, which leads to plant competition, poor population quality, lodging and low yields (Zhang et al. 2019). To decrease competition among plants and increase peanut yields, the Shandong Academy of Agricultural Sciences developed a high-yield cultivation technique for monoseeding precision sowing, which was ranked as the main technology by the Ministry of Agriculture and Rural Affairs for five consecutive years, from 2015 to 2019 and was promulgated as the national agricultural industry standard (Zhang et al. 2019). Several investigations have been performed to reveal the yield-increasing mechanisms of monoseeding precision sowing involved in ontogenetic development and population structures (Liang et al. 2015; Zhang et al. 2015; Zhang et al. 2019). However, until now, no studies have sought to clarify the suitable plant population densities for monoseeding patterns in Southern China.

In addition, paclobutrazol, which is one of the most potent plant growth retardants and is reported to decrease stem length (Rademacher 1990), reorient the distribution of assimilations to adjust the source-sink balance(Kuai et al. 2017) and increase peanut seed yields (Senoo and Isoda 2003), has been used in peanut production for many years. Its triazoles alter the balance of important plant hormones, including gibberellic acid, abscisic acid and cytokinins (Upreti et al. 2013). Several studies have concluded that spraying paclobutrazol could inhibit plant growth above-ground, significantly reducing the accumulation of assimilates in the leaves and promote their transport and distribution to the roots and seeds, making the roots and stems thicker and stronger (Senoo and Isoda 2003; Cheng et al. 2006).
${ }^{1}$ College of Agriculture, South China Agricultural University, Guangzhou, 510642, China.

${ }^{2}$ Biotechnology Research Center, Shandong Academy of Agricultural Science, Jinan, 250100, China.

\#These authors have contributed equally to this work.

Corresponding Author: Lei Zhang, College of Agriculture, South China Agricultural University, Guangzhou, 510642, China.

Email: zhanglei@scau.edu.cn

How to cite this article: Chen, T., Zhang, J., Wang, X., Zeng, R. and Zhang, L. (2022). Improving Peanut Growth and Yield Responses with Monoseeding and Paclobutrazol Applications in Southern China. Legume Research. DOI: 10.18805/LRF-643.

Submitted: 20-07-2021 Accepted: 13-12-2021 Online: 28-01-2022

Furthermore, interactions between plant populations and paclobutrazol applications have been reported for several crops, such as potato (Esmaielpour et al. 2011; Carvalho et al. 2019) and lentil (Effendi et al. 1989)However, there have been no relevant studies on the responses of peanut plants to changes in plant population and paclobutrazol applications with different seeding patterns, especially in Southern China. Consequently, the purpose of this study was to determine the effects of different plant population densities and paclobutrazol applications on peanut growth and yield, with mono- and double seeding patterns, in Southern China.

\section{MATERIALS AND METHODS}

Field experiments were carried out in 2019, at the South China Agricultural University Experimental Station in Guangzhou $\left(23^{\circ} 5^{\prime} \mathrm{N}, 113^{\circ} 23 \mathrm{E}\right)$, Guangdong, China. The experimental farms were located at the Pearl River Delta, which is characterized by a subtropical monsoon climate. The soil in the experimental field was lateritic soil and the total $\mathrm{N}, \mathrm{P}$ and $\mathrm{K}$ concentrations in the top $20 \mathrm{~cm}$ were 0.990 
$\mathrm{g} \mathrm{kg}^{-1}, 0.479 \mathrm{~g} \mathrm{~kg}^{-1}$ and $13.4 \mathrm{~g} \mathrm{~kg}^{-1}$, respectively and $\mathrm{a}$

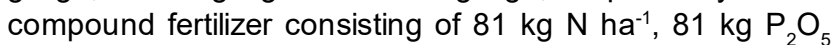
ha"1 and $81 \mathrm{~kg} \mathrm{~K}_{2} \mathrm{O} \mathrm{ha}^{-1}$, was applied before sowing. $\mathrm{A}$ commercial peanut cultivar (Arachis hypogaea 'Huayu 22') was selected because of its widespread agricultural use. The experiment included two different seeding methods (monoseeding and double seeding), three plant population densities (D1: 294265 plants ha-1, D2: 235410 plants ha $^{-1}$ and D3: 196170 plants $\mathrm{ha}^{-1}$ ) and three different concentrations of paclobutrazol (P0, $0 \mathrm{mg} \mathrm{L}^{-1}$; P125, 125 $\mathrm{mg} \mathrm{L}^{-1}$ and $\left.\mathrm{P} 250,250 \mathrm{mg} \mathrm{L}^{-1}\right)$, used to generate 12 treatments. The peanuts were planted on March 8, 2018. The peanut seeds were spaced with $42.5 \mathrm{~cm}$ between the rows and dropped into holes at distances of $8 \mathrm{~cm}, 10 \mathrm{~cm}$ and $12 \mathrm{~cm}$, in the rows for monoseeding and $16 \mathrm{~cm}, 20 \mathrm{~cm}$ and $24 \mathrm{~cm}$ in those for double seeding and this generated the D1, D2 and D3 plant densities, respectively.

At harvest, 10 plants were randomly selected from each plot and the main stem height and the diameter of the third internode, counted from the bottom of the main stem, were measured. Six plant samples were collected from each plot and separated into leaves, roots, pods and stems. Each fresh organ was dried at $105^{\circ} \mathrm{C}$ for $30 \mathrm{~min}$, followed by $80^{\circ} \mathrm{C}$, to a constant dry weight. The contribution rate of the root/ stem/leaf was equal to the total weight of a single plant and the stem/leaf ratio $=$ stem/leaf weight. The SPAD values in the functional leaves (third upper fully expanded leaves of the main stem) were determined using a chlorophyll meter (SPAD-502, Konica Minolta Sensing Inc., Osaka, Japan). The net photosynthetic rate $(\mathrm{Pn})$ of the third upper fully expanded leaveswas measured using a LI-6400 portable photosynthesis system (LI-COR, Lincoln, NE, USA), with a $6 \mathrm{~cm}^{2}$ leaf-area chamber. Three representative plants from each treatment were measured between 9:00 and 11:00 a.m.

Six consistent plants were sampled from each plot to count the number of pods per plant. All pods from the peanut plants were collected and air-dried for 15 days. The 100-pod weight and shelling percentages were measured in accordance with previously described methods (Zhang et al. 2020).

Data were processed using SPSS 16.0 (SPSS, Chicago, IL, USA). Relative changes (RC) were calculated as follows: $\mathrm{RC}=($ (paclobutrazol application treatment average value/ plant population densities treatment average values-average control values)/average control values) $x$ 100. All data are presented as the mean ( $\pm S D$ ) of three replicates $(n=3)$. When the difference between the mean values was greater than the LSD $(P=0.05)$, they were considered significant. A three-way analysis of variance (ANOVA) with a randomized block design was used to assess the effects of the treatments. Origin 2018 was used to draw all figures.

\section{RESULTS AND DISCUSSION Plant height}

As the plant population density increases, the competition for the uptake of light increases and photo destruction of auxin does not occur, which causes the plant height to increase and the diameter of the stem to reduce (Kishorekumar 2006). In our study, with the same densities and different paclobutrazol applications, the height of the peanut plant showed a significant $(p<0.05)$ decrease with increasing paclobutrazol applications, for both the mono and double seeding patterns and the shortest peanut height was found with the P250 conditions in the D3 population density (Fig 1); these results were similar to Andrzejewska et al. (2011), who conducted the effect of sowing rate on the yield of the fruits of milk thistle.

\section{Stem diameter}

The peanut stem diameters showed a slight increase, but insignificant, as the plant populations decreased and the stem diameter with the D3 treatment was greater than that with the D1 treatment, except for P0 in the monoseeding and P125 in the double seeding treatments (Fig 2). The thickest stems were obtained with P125 and P250 in the D3 treatment. After the paclobutrazol applications, the stem diameter increased significantly in the different plant

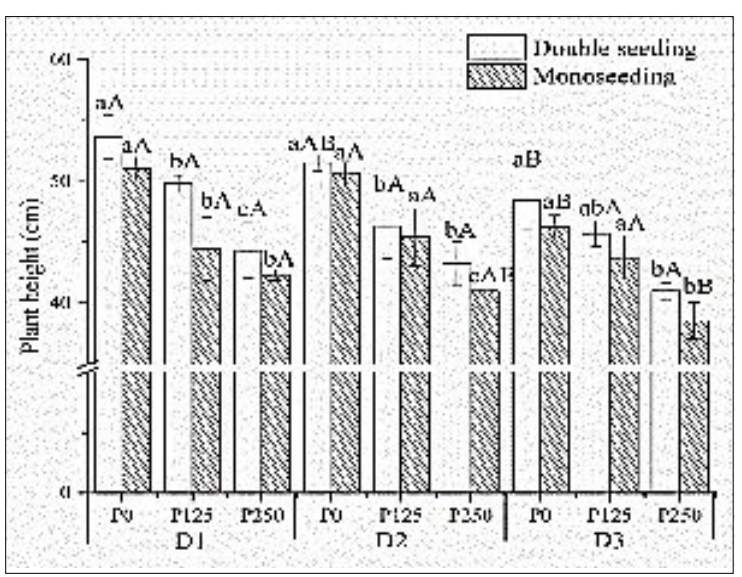

Fig 1: Effect of plant population density and paclobutrazol application on peanut plant height under different seeding patterns.

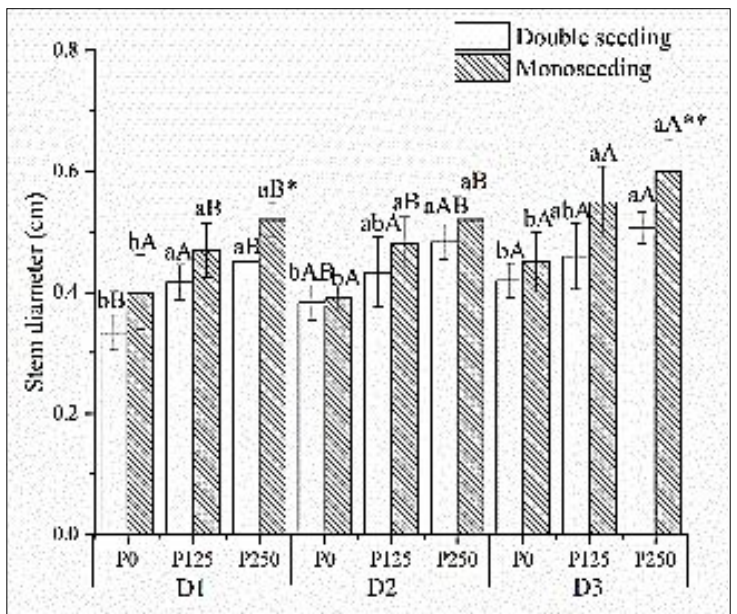

Fig 2: Effect of plant population density and paclobutrazol application on the stem diameter of peanut under different seeding pattern. 
population densities with the monoseeding pattern, whereas a significant difference $(p<0.05)$ was found only with the D1 treatment in the double seeding pattern. In addition, the presence of neighboring plants in double seeding could reduce and alter the light quality to other plants and induce shade avoidance response (SAR) (Gommers et al. 2013), which results in stem elongation and stem diameter reduction (Page et al. 2010), which affects yield (Ruberti et al. 2012).

\section{Chlorophyll content and net photosynthesis rate}

For the SPAD values, significant differences $(p<0.05)$ among the different plant populations were observed in the P0 treatment in both seeding patterns and the P250 in the monoseeding pattern, whereas no significant differences were observed with the other paclobutrazol applications (Fig 3). The highest SPAD value and net photosynthesis rate were observed in the P250 in both seeding patterns. Chlorophyll content increased after the paclobutrazol applications and might contribute to the synthesis of cytokinin upgrade (Gopi et al. 2007) or inhibit the cycling of geranylgeranyl pyrophosphate (GGPP) into ent-Kaurene during the biosynthesis of gibberellin (Rademacher 2000), which stimulates the biosynthesis of chlorophyll, as verified in wheat (Moradi et al. 2017) and rice (Elanchezhian et al. 2015).

\section{Dry matter accumulation}

The stem, root, pod and total biomass increased significantly $(p<0.05)$ as the paclobutrazol applications increased, while the leaf biomass showed the opposite trend and the aboveground biomass showed no significant differences among these treatments with either seeding pattern (Table 1). However, with the same paclobutrazol application and different plant populations, only the pod and total biomass increased significantly as the plant population densities decreased in both seeding patterns. However, this increasing trend was more obvious in the monoseeding pattern than in the double seeding pattern, whereas the leaf biomass did not differ with the different plant population densities. In addition, the highest root and stem biomasses were observed in the D3 populations, for both seeding patterns, except the root biomass in the double seeding pattern.

\section{Organ contribution rate}

Paclobutrazol applications significantly $(p<0.05)$ increased the stem contribution rate in the D2 in both seeding patterns (Table 2). The highest stem contribution rate was found with the P250 treatment with D3, in the double seeding pattern. However, the stem contribution rates in P125 and P250 of D2 and D3 were higher than those in D1 with the double seeding pattern. No significant differences in the root contribution rates were observed in the D2 and D3 of the monoseeding pattern and the D1 and D2 of the double seeding pattern, for each plant population density and different paclobutrazol applications. Paclobutrazol applications significantly increased the root contribution rate in D1 of the monoseeding pattern and D3 of the double seeding pattern and the highest value was observed in the P250 treatment. As the paclobutrazol applications increased, the leaf contribution rates in the D1 with the monoseeding pattern decreased and the highest leaf contribution rate appeared with the PO treatment. However, for each paclobutrazol application the different plant population density showed no significant differences in the double seeding pattern and the P125 in the different plant population densities of the monoseeding pattern. As the plant population densities decreased for each paclobutrazol application, the leaf contribution rates decreased and the highest leaf contribution rate was found in the P0 and P250 of the D1 treatment.

There was a significant difference in the pod contribution rates among the different paclobutrazol applications with the same plant population densities, whereas no significant differences in the pod contribution rates were observed among the different plant population densities with the same paclobutrazol applications, in either seeding pattern. As for the contribution rate of the different organs, there were significant differences in the leaf and pod contribution rates with the same plant populations, after different paclobutrazol

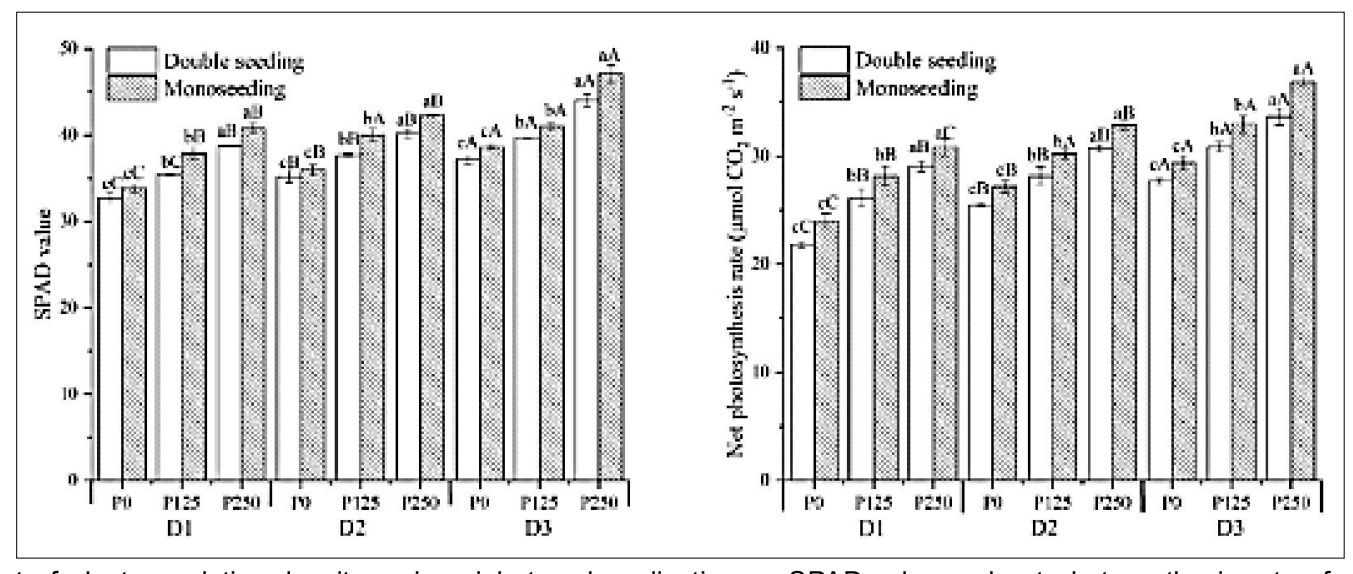

Fig 3: Effect of plant population density and paclobutrazol application on SPAD value and net photosynthesis rate of peanut under different seeding pattern. 


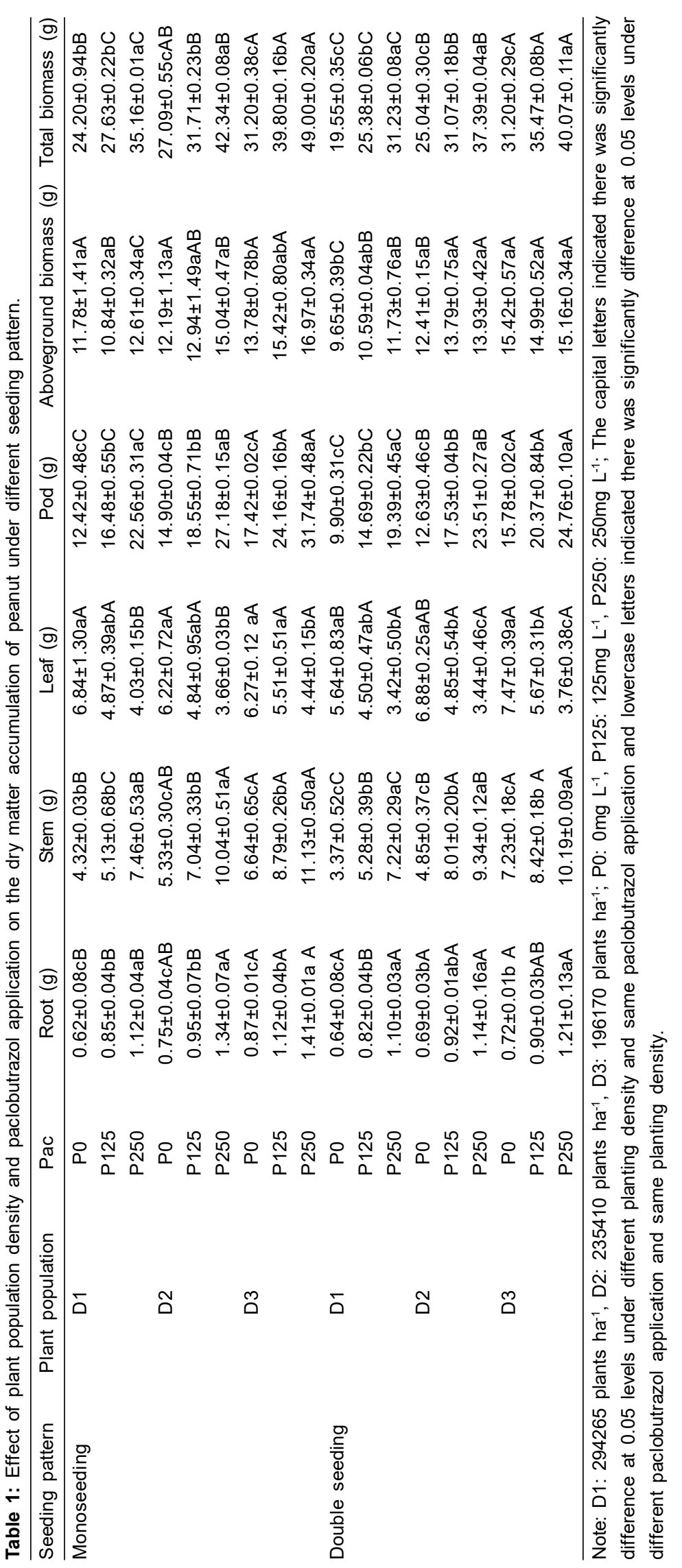




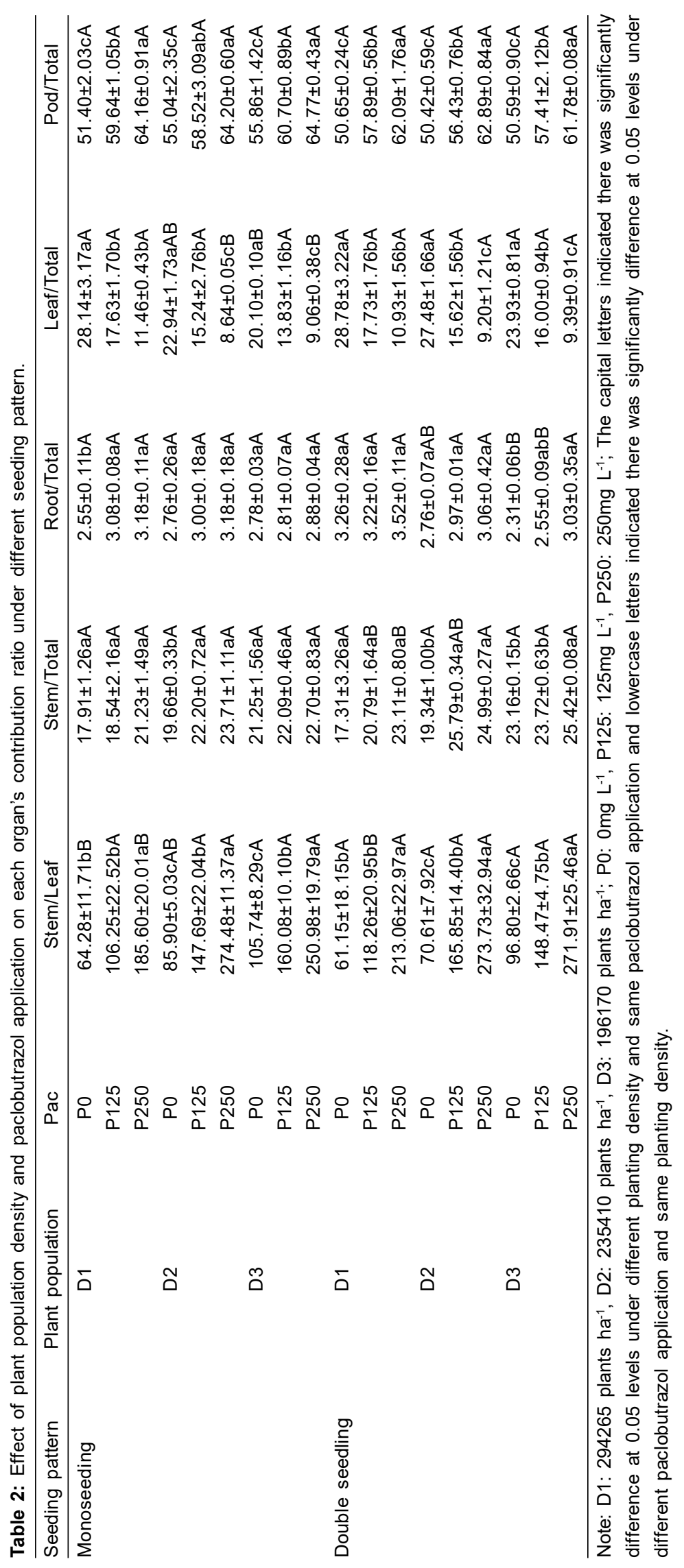




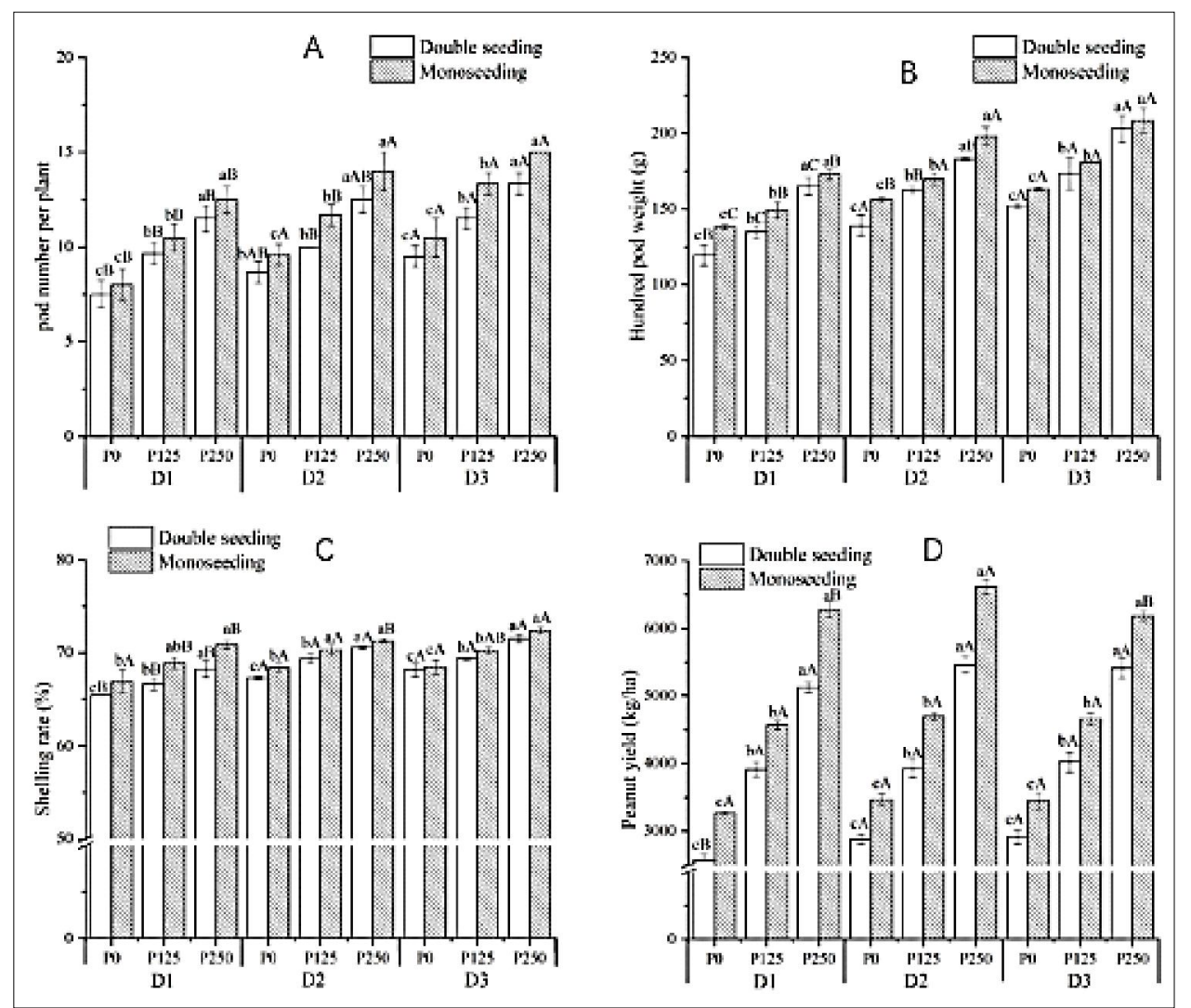

Fig 4: Effect of plant population density and paclobutrazol application on yield and yield components of peanut under different seeding pattern.

applications, which means that paclobutrazol applications might increase the amount of dry substance allocated to the pods rather than to the leaves of the peanut and increased the peanut yield for all treatments in our study. These results are consistent with the conclusions previously drawn by Kuai et al. (2017) and Esmaielpour et al. (2011).

\section{Yield and yield components}

A significant $(p<0.05)$ difference in the shelling rate among the different paclobutrazol applications was observed with the double seeding pattern and D3 treatment in the monoseeding pattern, whereas the highest shelling rate for the D1 and D2 treatments from the monoseeding pattern was observed in the P250 and P125 and P250 treatments, respectively (Fig 4). However, with the same paclobutrazol applications and different plant population densities, no significant differences in pod number per plant were observed among the different plant populations in both seeding patterns and the highest pod number per plant was observed in the P250 of the D3 in the double seeding pattern and the P250 of the D2 and D3 in the monoseeding pattern. A significant difference $(p<0.05)$ in the hundred pod weight among the different plant populations was shown for the $\mathrm{P} 125$ and $\mathrm{P} 250$ in the double seeding pattern and the P0 in the monoseeding pattern, while the other treatments showed no significant differences and the highest hundred pod weight was observed in the P250 of the D3 in the double seeding pattern and P250 of the D2 and D3 in the monoseeding pattern. In addition, there were no significant differences in the peanut yields among the different plant populations, with the same paclobutrazol applications, whereas the peanut yields from the monoseeding pattern were higher than those from the double seeding pattern and the highest peanut yield was observed in the P250 of the D2 treatments in the monoseeding pattern, indicating that the D2 plant population with the P250 paclobutrazol application, was the best combination for peanut cultivation in Southern China. However, this experiment was conducted only in southern China, but the soil type and climate condition in the peanut production areas may varied significantly. Therefore, further research is needed to conducted in different soil type and different peanut production areas.

\section{CONCLUSION}

In summary, paclobutrazol applications significantly decreased the plant height and increased the stem diameter, SPAD value and net photosynthesis rate with the same plant population density, in both seeding patterns, while no significant differences were observed with the same paclobutrazol application within different plant population densities. The highest peanut yield was observed with P250 and the D2 treatment in the monoseeding pattern, owing to 
the significant changes in the pod number per plant, hundred pods weights, induced by paclobutrazol application under the same plant population density and can be used for future peanut production in Southern China.

\section{ACKNOWLEDGEMENT}

This study was supported by the National Key RandD Program of China (2020YFD1000905), the Key Science and Technology Planning Project of Guangdong Province (2019B020214003) and the Guangdong Technical System of Peanut and Soybean Industry (2021KJ136-05).

\section{REFERENCES}

Andrzejewska, J., Sadowska, K. Mielcarek, S. (2011). Effect of sowing date and rate on the yield and flavonolignan content of the fruits of milk thistle [Silybum marianum (L.) Gaertn.] grown on light soil in a moderate climate. Industrial Crops and Products. 33(2): 462-468.

Carvalho, F.J., Carneiro, L.B., Benett, C.G.S., Benett, K.S.S., Martins, A.S., Silva, A.T.D. Seleguini, A. (2019). Plant density and application of growth regulator to tomato crop for industrial processing. Revista Colombiana de Ciencias Hortícolas. 13(3).

Cheng, Z., Xu, G., Li, Y. Wang, Y. (2006). Effect of paclobutrazol on growth, yield and quality of peanut under middle and low yield. Journal of Peanut Science. 35: 32-36.

Effendi, H., Hill, G. Field, R. (1989). The effect of plant population and growth regulators on growth and yield of lentil (Lens culinaris Medik.) cv. Olympic. Proceedings of the Agronomy Society of New Zealand.

Elanchezhian, R., Haris, A., Kumar, S. Singh, S. (2015). Positive impact of paclobutrazol on gas exchange, chlorophyll fluorescence and yield parameters under submergence stress in rice. Indian Journal of Plant Physiology. 20(2): 111-115.

Esmaielpour, B., Hokmalipour, S., Jalilvand, P. Ghobad Salim. (2011). The investigation of paclobutrazol effects on growth and yield of two potato (Solanum tuberosum) cultivars under different plant density. Journal of Food, Agriculture and Environment. 9(3 and 4): 289-294.

Gommers, C.M.M., Visser, R.J.W., Onge, K.R.S., Voesenek, L.A.C. Pierik, R. (2013). Shade tolerance: when growing tall is not an option. Trend in Plant Science. 18(2): 65-71.

Gopi, R., Jaleel, C.A., Sairam, R., Lakshmanan, G., Gomathinayagam, M. Panneerselvam, R. (2007). Differential effects of hexaconazole and paclobutrazol on biomass, electrolyte leakage, lipid peroxidation and antioxidant potential of Daucus carota L. Colloids and Surfaces B: Biointerfaces. 60(2): 180-186.
Kishorekumar, A. (2006). Differential effects of hexaconazole and paclobutrazol on the foliage characteristics of Chinese potato (Solenostemon rotundifolius Poir., J.K. Morton). Acta Biologica Szegediensis. 50: 127-129.

Kuai, J., Li, X., Yang, Y. Zhou, G. (2017). Effects of paclobutrazol on biomass production in relation to resistance to lodging and pod shattering in Brassica napus L. Journal of Integrative Agriculture. 16(11): 2470-2481.

Liang, X.Y., Guo, F., Zhang, J.L., Meng, J.J., Li, L., Wan, S.B. Li, X.G. (2015). Effects of single-seed sowing on canopy microenvironment, photosynthetic characteristics and pod yield of peanut (Arachis hypogaca). Chinese Journal of Applied Ecology. 26: 3700-3706.

Moradi, S., Baninasab, B., Gholami, M. Ghobadi, C. (2017). Paclobutrazol application enhances antioxidant enzyme activities in pomegranate plants affected by cold stress. The Journal of Horticultural Science and Biotechnology. 92(1): 65-71.

Page, E.R., Tollenaar, M., Lee, E.A., Lukens, L. Swanton, C.J. (2010). Shade avoidance: An integral component of crop-weed competition. Weed Research. 50: 281-288.

Rademacher, W. (1990). New types of plant growth retardants: Additional perspectives for practical application in agriculture and horticulture. Plant Growth Substances. 1988, Springer: 611-618.

Rademacher, W. (2000). Growth retardants: Effects on gibberellin biosynthesis and other metabolic pathways. Annual Review of Plant Biology. 51(1): 501-531.

Ruberti, I., Sessa, G., Ciolfi, A., Possenti, M., Carabelli, M. Morelli, G. (2012). Plant adaptation to dynamically changing environment: The shade avoidance response. Biotechnology Advances. 30: 1047-1058.

Senoo, S. and Isoda, A. (2003). Effects of paclobutrazol on dry matter distribution and yield in peanut. Plant Production Science. 6(1): 90-94.

Upreti, K.K., Reddy, Y., Prasad, S.S., Bindu, G., Jayaram, H. Rajan, S. (2013). Hormonal changes in response to paclobutrazol induced early flowering in mango cv. Totapuri. Scientia Horticulturae. 150: 414-418.

Zhang, G.C., Dai, L.X., Ding, H., Ci, D.W., Ning, T.Y., Yang, J.S., Zhao, X.H., Yu, H.Q. Zhang, Z.M. (2020). Response and adaptation to the accumulation distribution of phtosynthetic product in peanut under salt stress. Journal of Integrative Agriculture. 19: 690-699.

Zhang, J.L., Geng, Y., Guo, F., Li, X. Wan, S.B. (2019). Research progress on the mechanism of improving peanut yield by single-seed precision sowing. Journal of Integrative Agriculture. 18: 2-10.

Zhang, J.L., Guo, F., Yang, D.Q., Meng, J.J., Yang, S., Wang, X.Y., Tao, S.X., Li, X.G. B, W.S. (2015). Effects of single-seed precision sowing on population structure and yield of peanuts with super-high yield cultivation. Scientia Agricultura Sinica. 48: 3757-3766. 